\title{
Preparation and Characterization of Some Magnetic Nanocomposites of Biodegradable Polyurethane Based on (s)-histidine
}

\author{
Elaheh Gharehkhani \\ Department of Chemistry, Faculty of Engineering, \\ Islamic Azad University, Saveh Branch, Saveh, Iran.
}

http://dx.doi.org/10.13005/bbra/2128

(Received: 10 April 2016; accepted: 07 June 2016)

\begin{abstract}
Recycling the polymeric materials into the cycle of nature is one of the concerns of scientists; this has been possible through using natural or synthetic polymers. In this study, new polyurethanes containing optically active monomers and ester linkages were developed by prepolymer method. Nano zero valent iron (ZVI) particles that were synthesized by co-precipitation method, were well dispersed in the polymeric matrix with different percentage amounts in the presence of the ionic liquid via in-situ polymerization technique. The accuracy of monomer synthesis, all prepolymers and polyurethanes was confirmed by typical spectroscopy techniques of FTIR, ${ }^{1}$ HNMR, and CHN-O elemental analysis. To study the quality of ZVI and nanocomposites, nanoparticles (NPs) distribution instrument of X-ray (XRD), and scanning electron microscopy (SEM) were used. Properties such as thermal stability and thermal behavior and magnetic field were examined respectively by TGA, DTG, DSC and VSM techniques. Hydrolytic and enzymatic degradation of polyurethane composites with different weight percentages of $\mathrm{Fe}_{3} \mathrm{O}_{4}$ were studied.
\end{abstract}

Key words: Biodegradable; Polyurethane; Magnetic, Nanocomposite.

Polyurethanes are versatile polymers made of very soft foams to hard elastomers and, durable coatings in applications as diverse as medical, pharmaceutical, paint and coating industries ${ }^{1}$. From the reaction of Diisocyanate with diacids and polyols, they are easily prepared in a polyaddition reaction. Polyester-polyols or polyether-polyols with different aliphatic and aromatic structures are synthesized for this purpose $^{2}$. Generally, the structure-property relationships in a Polymer chain with its final characteristics is confirmed ${ }^{3}$. Depending on the type of requirements and the usages of special

\footnotetext{
* To whom all correspondence should be addressed. E-mail: e.gharehkhani@iau-saveh.ac.ir
}

soft $^{4}$ or hard ${ }^{5}$ segments, optically active side branches $^{6}$, ether bonds ${ }^{7}$, ester ${ }^{8-9}$, amide and imide ${ }^{10}$ functional groups are used to solve some polyurethane difficulties such as low thermal stability and poor mechanical strength ${ }^{11}$. With the increasing free spin rotation of polymer chains, ether links make them more flexible. By creating hydrogen bonds through amide groups, increase the solubility of the product ${ }^{12}$. Also the repetition of amide groups and the heterocyclic rings in polymer chains, improve the heat resistance of the polymers $^{13}$. The presence of ester bonds in the polyurethane's structure increases the likelihood of hydrolytic degradation in esterase ${ }^{14}$. Not returning to the cycle of nature is one of the issues that synthetic polymers are faced with. Natural polysaccharide-based biodegradable polymers 
such as chitosan and alginate ${ }^{15}$, although are used in the food and pharmaceutical industries, do not have the durability and thermal stability. Due to their potential applications in fields related to human life such as health and environmental protection, biodegradable polymers, in the last twenty years, have been regarded by researchers. Using biocompatible amino acid groups in the polymer chain structure, increases the solubility and causes the development of the applications as drug delivery agents ${ }^{16}$, detection of chiral and isolation of enantiomers in stationary phase of chromatography ${ }^{17}$, asymmetric synthesis catalyst, absorbent metal ions and biomaterials ${ }^{18}$. In an efficient way, the structure of optically active amino acids is entered into chemical structures of diol or dacid and used as a monomer to prepare polymers ${ }^{19-}$ ${ }^{23}$. It is expected that such synthetic polymers based on amino acids, are biocompatible and biodegradable. Invasion of microorganisms and fungi in soil and water of the sea or in the presence of esterase enzymes in in-vitro conditions has shown that the polyester-polyurethane compared with polyether-polyurethanes have greater biodegradability ${ }^{24-29}$. In addition to the structural modification of polyurethane chain, we can use inorganic nanoparticles, such as metal oxides, for example $\mathrm{TiO}_{2}{ }^{30}, \mathrm{ZnO}^{31}, \mathrm{SiO}_{2}{ }^{32}$ and $\mathrm{Fe}_{3} \mathrm{O}_{4}{ }^{33-35}$ to improve the required features. For example, the nanoparticle of zero-valent iron oxide (ZVI), although is now investigated in many articles, the application of it is regarded. Recently magnetic composite of polyurethane / $\mathrm{Fe}_{3} \mathrm{O}_{4}$ are produced and in some of them nanoparticles of $\mathrm{Fe}_{3} \mathrm{O}_{4}$ are used without surface modification and emulsifier capacity. Such as the research of $x u$ and et.al ${ }^{36}$ as well as Guo and et.al who developed polyurethane magnetic composites as microwave absorbers ${ }^{37}$. Surface modification of $\mathrm{Fe}_{3} \mathrm{O}_{4}$ nanoparticles with thiacalix ${ }^{4}$ arenes (TC4As) ${ }^{38}$ or TDGA have been reported by Mohammadi and et.al. They state that nanocomposites based on polyurethane with a more appropriate distribution of magnetic nanoparticles are biocompatible and non-toxic, so they are a good candidate for being used in biomedical applications ${ }^{39}$. In a study, covered $\mathrm{Fe}_{3} \mathrm{O}_{4}$ nanoparticles with bamboo carbon were used to destruct the quinoline in the treatment of a wastewater through "immobilized cell" method ${ }^{40}$. In another article magnetic nanoparticles coated with polyurethane are employed as a carrier immobilized microorganism for removing toluene and phenol from wastewater in a treatment. The magnetic field causes the degradation of phenol by accelerating the growth of microorganisms. Weak magnetic fields can stimulate bacterial growth effectively, shorten the cycle of growth and increase the activity of microorganisms that are useful for reproduction and metabolism ${ }^{41}$. In this paper, some new biodegradable polyurethane nanocomposites were prepared. With an optically active monomer based on (s)- histidine, some optically active polyester-polyurethane containing amide groups were prepared and then $\mathrm{Fe}_{3} \mathrm{O}_{4}$ magnetic nanoparticles in different weight ratio dispersed in the polyurethane chains using ionic liquid. The accuracy of synthesis, thermal and magnetic properties, and biodegradability of nanocomposites were investigated.

\section{EXPERIMENTAL}

\section{Materials}

N-methyl-2-pyrrolidone (NMP; 99.5\%), triphenyl phosphite (TPP; 98\%), (s)-histidine monohydrochloride monohydrate (98\%), and absolute ethanol (99\%), methanol (98\%), pyridine (py, 99\%), 4,4'-Methylene-bis-(4phenylisocyanate) MDI, Hexamethylene diisocyanate (HDI, 99\%), calcium chloride, dibutyltin dilurate (DBTD, 97\%), ethylene glycol (EG), hydroquinone (HQ), terephthaloyl dichloride (TPC, 98\%), dimethylsulfoxide (DMSO), N,Ndimethylformamide (DMF), $\mathrm{FeSO}_{4} \cdot 7 \mathrm{H}_{2} \mathrm{O}$, and $\mathrm{FeCl}_{3} \cdot 6 \mathrm{H}_{2} \mathrm{O}$ salts were obtained from Merck Co. Tosyl chloride (Aldrich, 99\%), adipoyl chloride (Aldrich, 98\%), and 1,2,4-benzenetricarboxylic acid 1,2-anhydride (TMA; 98\%) was purified by recrystallization from the mixture of acetic anhydride and acetic acid (1:5). N,N-Dimethylacetamide (DMAc) was purified by distillation under reduced pressure over barium oxide prior to polymerization. The other materials were used as obtained without further purification.

\section{Techniques}

Infrared measurements were performed on a Bruker-IFS48 FTIR spectrometer (Ettlingen, Germany). The spectra of solids were carried out using KBr pellet. Vibrational transition frequencies are reported in wave numbers $\left(\mathrm{cm}^{-1}\right)$. Band 
intensities are assigned as weak (w), medium (m), shoulder (sh), strong (s) and broad (br). Proton nuclear magnetic resonance ${ }^{1} \mathrm{H}$ NMR $(500 \mathrm{MHz})$ spectra were recorded in DMSO-d6 solution using a Bruker Avance 500 (GmbH, Germany). Tetramethyl silane (TMS) was used as an internal reference. Multiplicities of proton resonance are designated as singlet (s), doublet (d), doublet of doublet (dd) and multiplet $(\mathrm{m})$. Elemental analyses were perfumed by a CHN-O Rapid Heraeus elemental analyzer (Wellesley, MA). Inherent viscosities were measured by a standard procedure using a Cannon Fenske Routine Viscometer (Germany) at a concentration of $0.5 \mathrm{~g} \mathrm{dL}-1$ in NMP at $30^{\circ} \mathrm{C}$. Differential scanning calorimetric (DSC) and thermogravimetric analysis (TGA) were recorded in nitrogen atmosphere at a heating rate of $30^{\circ} \mathrm{C} /$ min on a Stanton Redcraft STA-780 (London, UK). Specific rotations were measured by a Perkin Elmer241 Polarimeter (Germany). Wide angle X-ray diffraction patterns (XRD) were performed at room temperature on an X-ray diffractometer (Siemens model D 5000, Germany) using Ni-filtered CuKá radiation $(40 \mathrm{kV}, 25 \mathrm{~mA})$ with scanning rate of $3 \%$ min. The morphology of the polyurethane (PU)/ $\mathrm{Fe}_{3} \mathrm{O}_{4}$ nanocomposites powders during milling was investigated by means of scanning electron microscopy (SEM; Philips, XL30) on gold-coated powders. The magnetic properties of $\mathrm{Fe}_{3} \mathrm{O}_{4}$ nanoparticles and composites were studied with Vibrating sample magnetometer (VSM) by Central Laboratory of kashan university (Isfahan-Iran).

\section{Methods}

Preparation of magnetic $\mathrm{Fe}_{3} \mathrm{O}_{4}$ nanoparticles

The typical synthesis procedure of $\mathrm{Fe}_{3} \mathrm{O}_{4}$ nanoparticles is similar to the method described $\mathrm{in}^{41}$. Twenty grams $\mathrm{NaOH}$ was dissolved in $250 \mathrm{~mL}$ deionized water which was deoxygenated by bubbling $\mathrm{N}_{2}$ gas for $30 \mathrm{~min}$ at 1,000g stirring for 10 min. In another beaker, $0.85 \mathrm{~mL}$ of $12.1 \mathrm{~N} \mathrm{HCl}$ and $25 \mathrm{~mL}$ deionized water was mixed, and then $8.1 \mathrm{~g}$ of $\mathrm{FeCl}_{3} \cdot 6 \mathrm{H}_{2} \mathrm{O}$ and $3.1 \mathrm{~g}$ of $\mathrm{FeSO}_{4} \cdot 7 \mathrm{H}_{2} \mathrm{O}$ were successively dissolved in the solution under stirring. Then, the resultant solution was added drop-wise into the above-mentioned $\mathrm{NaOH}$ solution under vigorous stirring, and black precipitate was obtained and harvested by centrifugation, and then washed with deionized water and ethanol several times, respectively, and finally dried in the air at $80^{\circ} \mathrm{C}$ for $2 \mathrm{~h}$. Then, the harvested $\mathrm{Fe}_{3} \mathrm{O}_{4}$ nanoparticle composite was used for the next step in the preparation of the magnetic $\mathrm{PU} / \mathrm{Fe}_{3} \mathrm{O}_{4}$ composites.

\section{Synthesis of diacids}

In this step first, $0.351 \mathrm{~g}$ of (s)-histidine (2 mmol) were stirred in $8 \mathrm{ml}$ of NMP at $0{ }^{\circ} \mathrm{C}$ for 30 minutes. A $50 \mathrm{~mL}$, two-necked, round-bottomed flask equipped with a magnetic stirrer, nitrogen gas inlet tube, and calcium chloride drying tube was charged with the mixture. Then about $1.0 \mathrm{~mL}$ of propylene oxide was added, and after a few minutes $0.183 \mathrm{~g}$ of adipoyl chloride $(1 \mathrm{mmol})$ was added. The temperature was raised to room temperature and the solution was continuously stirred for 6 hrs. Polyamide was precipitated by pouring the flask content into methanol. Then it was filtered, washed with hot water and methanol and dried overnight under vacuum at $100^{\circ} \mathrm{C}$. (Terephthaloyl chloride was used in the same way.) Two types of diacid as chain extender were prepared in this step. The yield of APC diacid $84.5 \%$ and TPC diacid $95.0 \%$, and their specific optical rotations, $[\alpha] 25 \mathrm{D}$ : -78.6 and -55.9 [0.0520 $\mathrm{g}$ and $0.0500 \mathrm{~g}$ in $10 \mathrm{~mL}$ of DMF] were obtained.

\section{Synthesis of polyester-polyols}

To prepare the polyester - polyol oligomers or diol containing ester linkages, first, the catalytic solution contains $1.068 \mathrm{~g}(5.6 \mathrm{mmol})$ of tosyl chloride in $2 \mathrm{ml}$ of pyridine was stirred for half an hour and then $2 \mathrm{ml}$ of DMF as solvent was added to the mixture. In a case that EG was used in diol synthesis, $0.744 \mathrm{~g}(1.2 \mathrm{mmol})$ of ethylene glycol and to provide diol solution with HQ, $0.132 \mathrm{~g}(1.2$ $\mathrm{mmol}$ ) of hydroquinone, were dissolved in $1 \mathrm{ml}$ of pyridine. To prepare the solution of dicarboxylic acid, $0.548 \mathrm{~g}(1 \mathrm{mmol})$ of the synthesized diacid in the previous step was dissolved in $4.5 \mathrm{ml}$ of DMF. Finally, the acid solution was poured in a $50 \mathrm{ml}$, two-necked, round-bottomed flask equipped with a magnetic stirrer, nitrogen gas inlet tube, and condenser, and then catalyst solution was gradually added within 20 minutes to the flask solution. The diol solution was then added to the mixture and stirred for half an hour. Then, the temperature was increased to $120^{\circ} \mathrm{C}$ and stirred at this temperature for 2 hours continuously. The resulting product was work up with pouring in to $50 \mathrm{ml}$ of water and methanol (1:1) and stirring for 15 minutes. Finally, the resulting precipitates filtered, washed with water and then dried for 2 hours at $80^{\circ} \mathrm{C}$ in a vacuum 
oven. Four different kinds of polyester-polyols were synthesized in the same way.

\section{Synthesis of polyurethanes}

At each batch, a solution of $0.1 \mathrm{mmol}$ of polyester-polyol derived from the previous step with $0.025 \mathrm{~g}(0.1 \mathrm{mmol})$ of MDI or $0.017 \mathrm{~g}(0.1 \mathrm{mmol})$ of HDI in $1 \mathrm{ml}$ of NMP as solvent was prepared and 0.01 grams of catalyst (DBTD) was added to the mixture then, mixed for 30 minutes at room temperature. The temperature gradually increased to $110 \mathrm{R}$ " $\mathrm{C}$ and the reaction was completed in 7 hours. The resulting mixture was cooled and was poured in $100 \mathrm{ml}$ of water. So polymer precipitates were isolated in water and separated. Finally, they dried at $90^{\circ} \mathrm{C}$ in the vacuum oven. Generally, 8 samples of polyurethanes were prepared this way.

\section{Preparation of polyurethane $/ \mathrm{Fe}_{3} \mathrm{O}_{4}$} nanocomposites

According to the yield at each batch, the required amounts of raw materials, solvents and catalyst for preparing one grams of polyurethane were calculated. Before curing stage, using catalyst, the amount $0.1 \mathrm{~g}$ of synthesized $\mathrm{Fe}_{3} \mathrm{O}_{4}$ nanoparticles and $0.1 \mathrm{~g}$ of ethyl methyl imidazolium bromide ionic liquid; [emim] Br were added to the solution and distributed by sonication method. Therefore, NPs in the in-situ polymerization were entrapped between the polymer chains during the polymerization to form a desirable composite. All nanocomposites were fine synthesized in the same way with different weight percentages up to $30 \%$ of NPs in the polymeric matrix.

\section{RESULTSAND DISCUSSION}

Optically active co-poly(ester amide urethane)s were prepared in three stages from chemical reactions. Two new optically active acids were synthesized from the reaction of (s)-histidine with adipoyl chloride or, terephthaloyl chloride in 1:1 molar ratio. Calcium chloride as water absorbent and propylene oxide as acid scavenger are used. Amide bonds were formed at this reaction step. Imidazolium side branch as polar heterocyclic rings and amide bonds are the advantages of this design of diacid, addition to the optically active properties.

\section{Characterization of diacids}

In Figure 1 the FT-IR spectra of optically active diacid based on APC are shown. Peaks in the range of $3410-2925 \mathrm{~cm}^{-1}$ are related to the $\mathrm{C}-\mathrm{H}$ bond stretching frequency, peaks in the range of $2345 \mathrm{~cm}^{-1}$ to amide $\mathrm{N}-\mathrm{H}$ stretching frequencies, spectrum in $1620 \mathrm{~cm}^{-1}$ to the frequency of the aromatic $\mathrm{C}=\mathrm{C}$ bond stretching and district peak in

Table 1. Characterization of diacids

\begin{tabular}{|c|c|c|c|c|c|}
\hline \multirow{2}{*}{$\begin{array}{l}\text { Diacid } \\
\text { Type }\end{array}$} & \multirow{2}{*}{$\begin{array}{l}\text { Formula } \\
{[\mathrm{Mw}]}\end{array}$} & \multirow[t]{2}{*}{ FT-IR $\left(\mathrm{cm}^{-1}\right)$} & \multirow[t]{2}{*}{${ }^{1} \mathrm{H}-\mathrm{NMR}$} & \multicolumn{2}{|c|}{ Elemental analysis } \\
\hline & & & & Calcd. & Found \\
\hline APC & $\begin{array}{l}\mathrm{C}_{18} \mathrm{H}_{24} \mathrm{~N}_{6} \mathrm{O}_{6} \\
{[420]}\end{array}$ & $\begin{array}{l}\text { 3410-3607 (O-H) acid, } \\
\text { 2925- } 3410 \text { (C-H), } \\
2345 \text { (-NH-) amide \& } \\
\text { imidazolium, } \\
1683 \text { (C=O) acid, } \\
1620 \text { (C=C) arom. \& } \\
\text { (C=O) amide, } 1150 \text {-1095 } \\
\text { (C-H) aliph. } 1008 \text { (C-C) } \\
\text { aliph.8 }\end{array}$ & $\begin{array}{l}1.35 \text { dd }\left(4 \mathrm{H}, \mathrm{CH}_{2}\right) ; \mathrm{h} \\
1.87 \mathrm{~d}\left(4 \mathrm{H}, \mathrm{CH}_{2}\right) ; \mathrm{g} \\
3.50 \mathrm{dd}\left(4 \mathrm{H}, \mathrm{CH}_{2}\right) ; \mathrm{f} \\
\\
5.12 \mathrm{~d}(2 \mathrm{H}, \mathrm{CH}) ; \mathrm{e} \\
7.52 \mathrm{~d}(2 \mathrm{H}, \text { aromatic }) ; \mathrm{d} \\
8.28 \text { s (2H, N-H aromatic); c } \\
8.54 \text { dd }(2 \mathrm{H}, \text { arom. }) ; \mathrm{b} \\
14.31 \text { s }(2 \mathrm{H}, \text { acid }) ; \mathrm{a} \\
8\end{array}$ & $\begin{array}{l}\mathrm{C}: 51.43 \\
\mathrm{H}: 5.71 \\
\mathrm{~N}: 20.00\end{array}$ & $\begin{array}{l}\mathrm{C}: 51.38 \\
\mathrm{H}: 5.70 \\
\mathrm{~N}: 19.89\end{array}$ \\
\hline TPC & $\begin{array}{l}\mathrm{C}_{20} \mathrm{H}_{20} \mathrm{~N}_{6} \mathrm{O}_{6} \\
{[440]}\end{array}$ & $\begin{array}{l}3560(\mathrm{O}-\mathrm{H}) \text { acid, } \\
3000-3410(\mathrm{C}-\mathrm{H}), \\
2235(-\mathrm{NH}-) \text { amide \& } \\
\text { imidazolium, } 1600(\mathrm{C}=\mathrm{O}) \\
\text { acid, } 1575(\mathrm{C}=\mathrm{C}) \text { aromatic \& } \\
(\mathrm{C}=\mathrm{O}) \text { amide, } 1165(\mathrm{C}-\mathrm{H}) \\
\text { aliphatic } 1005(\mathrm{C}-\mathrm{C}) \text { aliphatic } 8\end{array}$ & $\begin{array}{l}\left.3.52 \text { dd (4H, } \mathrm{CH}_{2}\right) ; \mathrm{g} \\
5.25 \text { d (2H, CH); f } \\
7.60 \text { d (2H, aromatic);e } \\
7.87 \text { s (4H, benzene);d } \\
8.35 \text { s (2H, N-H aromatic); c } \\
8.67 \text { dd (2H, arom.);b } \\
14.31 \text { s (2H, acid); a }\end{array}$ & $\begin{array}{l}\mathrm{H}: 4.54 \\
\mathrm{~N}: 19.09\end{array}$ & $\begin{array}{l}\mathrm{H}: 4.52 \\
\mathrm{~N}: 19.01\end{array}$ \\
\hline
\end{tabular}


$1683 \mathrm{~cm}-1$ can be attributed to stretching and amide and acid carbonyl groups. Peaks in the range of $1150-1008 \mathrm{~cm}^{-1}$ can be assigned to the aliphatic C$\mathrm{C}$ bonds and $\mathrm{C}-\mathrm{H}$ stretching frequencies.

The nuclear magnetic resonance spectrum ( ${ }^{1} \mathrm{H}-\mathrm{NMR}$ ) of optically active diacid (APC) can be seen in Figure 2. As it shown, amine hydrogen (N$\mathrm{H})$ and $\mathrm{C}-\mathrm{H}$ bond between two second types of amines in (s)-histidine around 8.3 and $8.4 \mathrm{ppm}$, it's aromatic hydrogen in $7.4 \mathrm{ppm}$, optically active $\mathrm{C}-\mathrm{H}$ bond in $5 \mathrm{ppm}$, mythylene $\left(\mathrm{CH}_{2}\right)$ histidine in range of 3.4 and 3.5 are located. Peaks related to hydrogen nuclear magnetic resonance of aliphatic methylene groups have appeared on the lower fields, in the range of 1 and $1.7 \mathrm{ppm}$.

\section{Characterization of prepolymers}

The reaction of an optically active diacid obtained from the previous step with one of two commercial diols, EG and HQ when the molar ratio of alcohol is higher than the diacid, causes to prepare some new diols, polyols and hydroxyl end groups oligomers. Ester bonds were formed at this step (fig.3).
CHN-O elemental analysis of two kinds of diacid, four types of diols and eight samples of polyurethanes which confirm validity of their synthesis were shown in Tables 1 and 2 . Polyurethanes containing amide and ester groups, and imidazolium side branches were synthesized by the reaction of the prepared prepolymers with commercial diisocyanates, HDI and MDI in the presence of a DBTD as catalyst and the gradual elimination remove of water.

\section{Characterization of polyurethanes (PUs) FTIR, ${ }^{1} \mathrm{H}$-NMR spectra, and elemental analysis of} PUs

The resulting PUs were characterized by FTIR, ${ }^{1} \mathrm{H}-\mathrm{NMR}$ and elemental analysis techniques. The data were shown in Table (2) and figure (5). All the polymers showed two almost broad characteristic FTIR absorption peaks at about 3050$3420 \mathrm{~cm}^{-1}$ related to amide N-H bands, and 1648$1661 \mathrm{~cm}^{-1}$ corresponding to the amide carbonyl and ester groups. It showed be mention that the broadness of peaks was attributed to the preformed

Table 2. Characterization of diols and polyurethanes

\begin{tabular}{|c|c|c|c|c|c|c|c|}
\hline \multirow[t]{2}{*}{ Comp. } & \multirow[t]{2}{*}{ Code } & \multirow[t]{2}{*}{ Formula } & \multirow[t]{2}{*}{$\mathrm{Mw}$} & \multirow[t]{2}{*}{ Type } & \multicolumn{3}{|c|}{ Elemental analysis } \\
\hline & & & & & C (\%) & $\mathrm{H}(\%)$ & $\mathrm{N}(\%)$ \\
\hline \multirow[t]{8}{*}{ Diol } & \multirow[t]{2}{*}{ APC-EG } & \multirow{2}{*}{$\mathrm{C}_{22} \mathrm{H}_{32} \mathrm{~N}_{6} \mathrm{O}_{8}$} & \multirow[t]{2}{*}{508} & Calcd. & 51.97 & 6.30 & 16.53 \\
\hline & & & & Found & 51.90 & 6.21 & 16.50 \\
\hline & \multirow[t]{2}{*}{ APC-HQ } & \multirow{2}{*}{$\mathrm{C}_{30} \mathrm{H}_{32} \mathrm{~N}_{6} \mathrm{O}_{8}$} & \multirow[t]{2}{*}{604} & Calcd. & 59.60 & 5.30 & 13.91 \\
\hline & & & & Found & 59.71 & 5.35 & 14.01 \\
\hline & \multirow[t]{2}{*}{ TPC-EG } & \multirow{2}{*}{$\mathrm{C}_{24} \mathrm{H}_{28} \mathrm{~N}_{6} \mathrm{O}_{8}$} & \multirow[t]{2}{*}{528} & Calcd. & 54.54 & 5.30 & 15.91 \\
\hline & & & & Found & 54.49 & 5.25 & 16.00 \\
\hline & \multirow[t]{2}{*}{ TPC-HQ } & \multirow{2}{*}{$\mathrm{C}_{32} \mathrm{H}_{28} \mathrm{~N}_{6} \mathrm{O}_{8}$} & \multirow[t]{2}{*}{624} & Calcd. & 61.54 & 4.49 & 13.46 \\
\hline & & & & Found & 61.60 & 4.46 & 13.30 \\
\hline \multirow[t]{16}{*}{ Polymer } & \multirow[t]{2}{*}{ APC-EG-HDI } & \multirow{2}{*}{$\mathrm{C}_{30} \mathrm{H}_{42} \mathrm{~N}_{8} \mathrm{O}_{10}$} & \multirow[t]{2}{*}{674} & Calcd. & 53.41 & 6.23 & 16.62 \\
\hline & & & & Found & 54.01 & 6.15 & 17.33 \\
\hline & \multirow[t]{2}{*}{ APC-EG-MDI } & \multirow{2}{*}{$\mathrm{C}_{37} \mathrm{H}_{40} \mathrm{~N}_{8} \mathrm{O}_{10}$} & \multirow[t]{2}{*}{756} & Calcd. & 58.73 & 5.29 & 14.81 \\
\hline & & & & Found & 60.00 & 5.30 & 15.02 \\
\hline & \multirow[t]{2}{*}{ APC-HQ-HDI } & \multirow[t]{2}{*}{$\mathrm{C}_{38} \mathrm{H}_{42} \mathrm{~N}_{8} \mathrm{O}_{10}$} & \multirow[t]{2}{*}{770} & Calcd. & 59.22 & 5.45 & 14.54 \\
\hline & & & & Found & 60.08 & 5.42 & 14.53 \\
\hline & \multirow[t]{2}{*}{ APC-HQ-MDI } & \multirow{2}{*}{$\mathrm{C}_{45} \mathrm{H}_{40} \mathrm{~N}_{8} \mathrm{O}_{10}$} & \multirow[t]{2}{*}{852} & Calcd. & 63.38 & 4.69 & 13.14 \\
\hline & & & & Found & 63.45 & 4.65 & 13.11 \\
\hline & TPC-EG-HD & $\mathrm{C}_{32} \mathrm{H}_{38} \mathrm{~N}_{8} \mathrm{O}_{10}$ & 694 & Calcd. & 55.33 & 5.48 & 16.14 \\
\hline & & & & Found & 55.28 & 5.43 & 16.02 \\
\hline & TPC-EG-MDI & $\mathrm{C}_{39} \mathrm{H}_{36} \mathrm{~N}_{8} \mathrm{O}_{10}$ & 776 & Calcd. & 60.31 & 4.64 & 14.43 \\
\hline & & & & Found & 60.51 & 4.66 & 14.62 \\
\hline & TPC-HQ-HDI & $\mathrm{C}_{40} \mathrm{H}_{38} \mathrm{~N}_{8} \mathrm{O}_{10}$ & 790 & Calcd. & 60.76 & 4.81 & 14.18 \\
\hline & & & & Found & 60.78 & 4.84 & 14.08 \\
\hline & TPC-HQ-MDI & $\mathrm{C}_{47} \mathrm{H}_{36} \mathrm{~N}_{8} \mathrm{O}_{10}$ & 872 & Calcd. & 64.68 & 4.13 & 12.82 \\
\hline & & & & Found & 64.50 & 4.30 & 12.49 \\
\hline
\end{tabular}


amide units and also polyamide backbones. The representative FTIR spectra of TPC-EG-HDI PU were brought in Figure 5. Not so broad peak in the area $3403 \mathrm{~cm}^{-1}$, secondary amines $\mathrm{N}-\mathrm{H}$ stretching frequency in the structure of histidine, peaks in the frequency range of $3403-2923 \mathrm{~cm}^{-1}$ tensile C-H bond, peaks in the range of $2300 \mathrm{Cm}^{-1}$ stretching frequencies $\mathrm{N}-\mathrm{H}$ amide, peak in an area $1600 \mathrm{Cm}^{-1}$ is related to stretching frequency of the aromatic $\mathrm{C}=\mathrm{C}$ bond stretching, amide carbonyl groups, created peak in area $1775 \mathrm{Cm}^{-1}$ is attributed to the ester carbonyl, and peaks in the range of 1244$1009 \mathrm{~cm}^{-1}$ return to stretching frequency of the aliphatic C-C and C-H bonds in ethylene and adipoyl. The absence of sharp peaks in the area $2270 \mathrm{~cm}^{-1}$, the stretching frequency of NCO indicates the purity of polyurethane without diisocyanate as raw material. Presence of a peak in the area $1718 \mathrm{~cm}^{-1}$, related to tensile frequency of polyurethane carbonyl groups proves the synthesis accuracy of the polymer.

The ${ }^{1} \mathrm{H}-\mathrm{NMR}$ of TPC-EG-HDI PU showed peaks in the region of $\delta=7.55-8.79 \mathrm{ppm}$ related to aromatic rings, and peaks for two kinds of amide and urethane $\mathrm{NH}$ groups appeared as singlet at ä $=$ 10.57 and $10.28 \mathrm{ppm}$. The other polymers showed similar peaks in the ${ }^{1} \mathrm{H}-\mathrm{NMR}$ spectra with differences in aromatic and aliphatic proton magnetic resonance fields. The elemental analysis results were in good agreement with calculated percentages for carbon, hydrogen and nitrogen contents in poly(ester-amide-urethane)s (PEAUs) repeating unit (Table 2).

\section{Solubility of PUs}

The solubility properties of PEAs were studied in different solvents (Table 3). Polymers were soluble in the polar aprotic solvents such as NMP, DMAc, DMF, DMSO, and m-cresol. The solubility of the polyesters was in the range of 2.1$2.8 \mathrm{~g} / \mathrm{dL}$. Good solubility of the polymer was mainly related to the presence of ester units, optically active groups, and polar (s)-histidine bulky pendant from diacid moieties. Difference in solubility of PUs was based on the structure of diol and diisocyanate moieties in the polymer backbone. The APC-EGHDI PU and APC-EG-MDI PU showed better solubility due to the fact that the related diols contained aliphatic bonds and were more flexible.

\section{Yield, inherent viscosity, and specific rotation of} PUs

Yields and inherent viscosities of obtained polymers via three different methods were compared and the results were differences in values. As the inherent viscosity is a good criterion for estimation of molecular weight, it was concluded that all the polymers showed reasonable molecular weights. Another important outcome was PUs obtained with aromatic linkages had higher viscosity and molecular weight in comparison to fully aliphatic ones.

Table 3. Solubility of poly(ester-amide-urethane)s

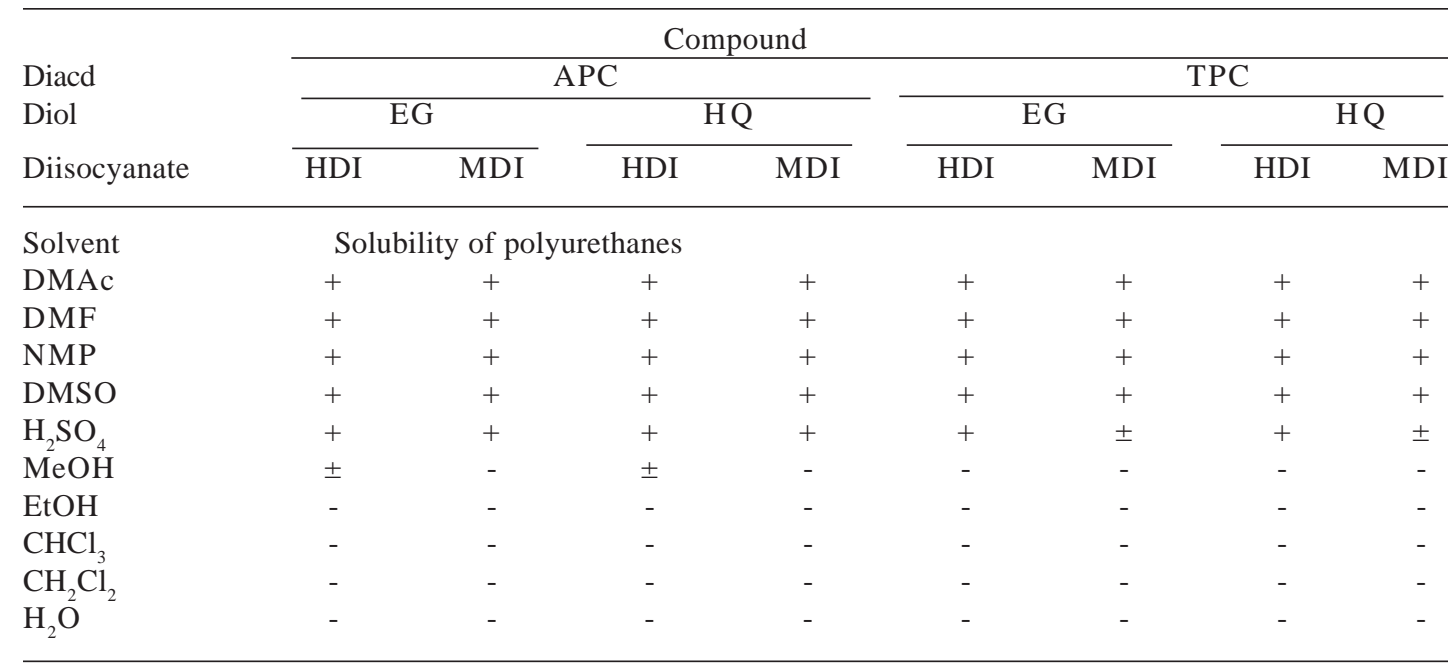

Concentration: $5 \mathrm{mg} \mathrm{ml}^{-1} ;(+)$ : soluble at room tempratuer, (-): insoluble, and $( \pm)$ : soluble with heating. DMAc: N,Ndimethyl acetamide; DMF: N,N-dimethyl formamide; NMP: N-methyl pyrolidone; DMSO: dimethyl sulfoxide, MeOH: methanol, EtOH: ethanol 
The inherent viscosity of the polymers was in range $0.18-0.49 \mathrm{dL} / \mathrm{g}$. The results of measurements showed that the synthesized polyurethane from the same monomers specially, aromatic monomers, had a good average chain length growth. Increased viscosity results in increased molecular weight, and then improves physical properties and thermal properties.

\section{Thermal properties of PUs}

Thermal properties of PEAs were evaluated with TGA and DTG under air atmosphere at a heating rate of $30^{\circ} \mathrm{C} / \mathrm{min}$. Thermal stability of the polymers was evaluated based on $\mathrm{T}_{0}$ (initial decomposition temperature), $\mathrm{T}_{10}$ (temperature for $10 \%$ weight loss), $\mathrm{T}_{\max }$ (maximum decomposition temperature) and residues of the polymers at 600 ${ }^{\circ} \mathrm{C}$ (char yield).

High thermal stability of the polymers was concluded according to the TGA data. It could be mainly related to aromatic and rigid structure of monomers. Because of the higher rigidity and symmetry of TPC and HQ in comparison to the other polymers, the highest thermal stability data was related to it. PEAUs containing aliphatic linkages (APC-EG-HDI and APC-EG-MDI) showed lowest thermal stability among the polymers due to the presence of weak aliphatic units in which reducing of thermal stability was intensified by increasing of aliphatic chains (APC-EG-HDI PU). However, its biodegradation seems more than the other PUs.

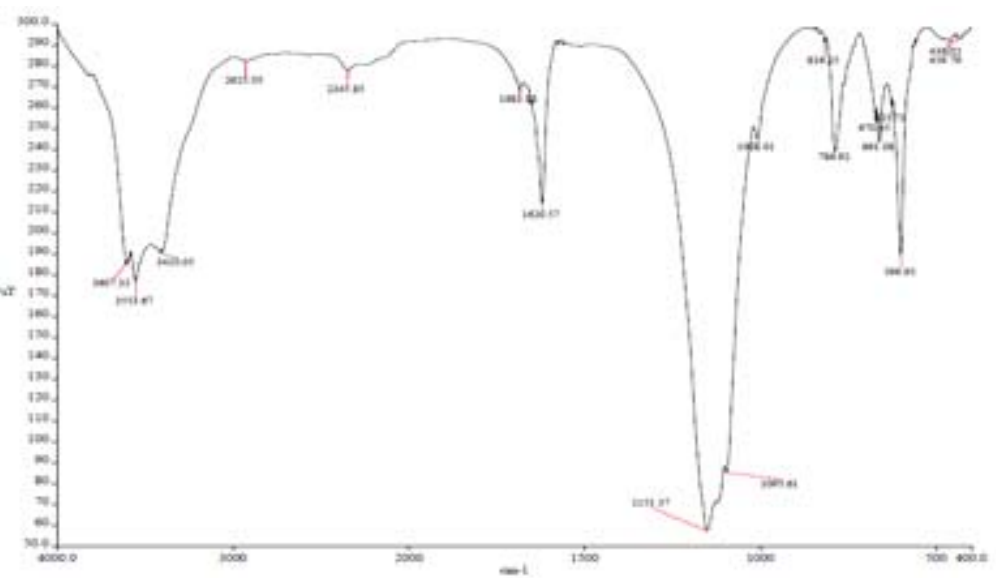

Fig. 1. FT-IR spectrum of optically active diacid based on APC

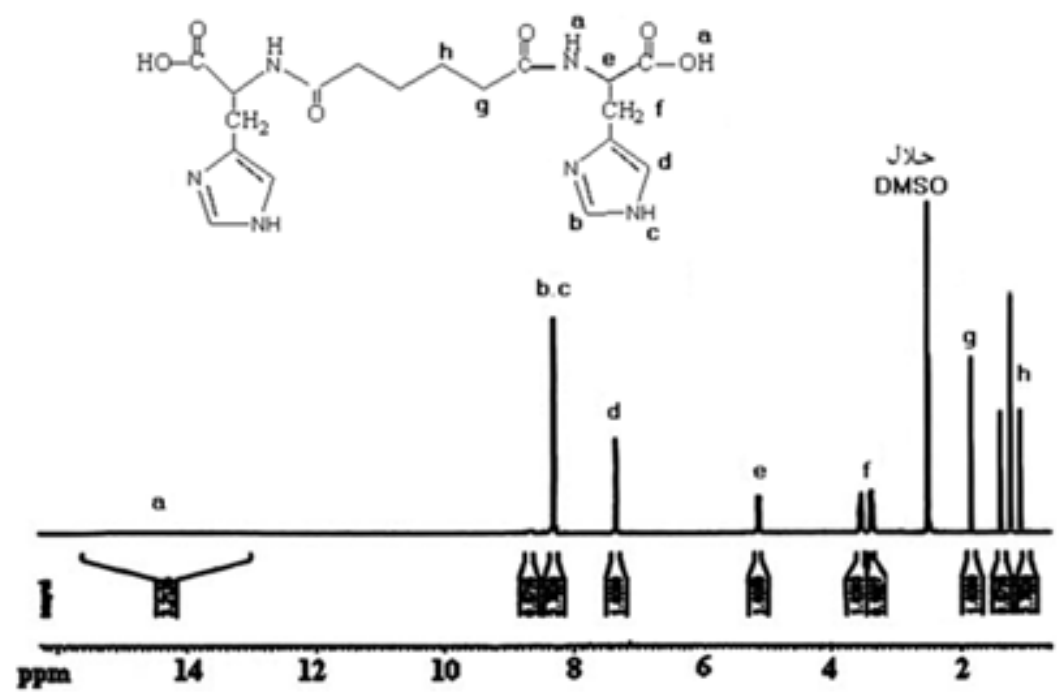

Fig. 2. ${ }^{1} \mathrm{H}-\mathrm{NMR}$ spectrum of optically active diacid based on APC 
All of the prepolymers and PUs showed optically active properties, and the specific rotations of PUs were measured in DMF at a concentration of $0.5 \mathrm{~g} / \mathrm{dL}$ at $25^{\circ} \mathrm{C}$ in the range 43.28 to -80.3 .

\section{Characterization of nanocomposites}

Although, all polyurethanes were synthesized and well characterized, their thermally stable, biocompatible, biodegradation and antibacterial were improved with preparing their related magnetic nanocomposites though introducing $\mathrm{Fe}_{3} \mathrm{O}_{4}$ in to polymer matrix. Among the PEAUs, APC-EG-HDI PU selected due to the appropriate growing polymer chain length then thermal stability properties and biodegradation ability. Magnetic nanoparticles (NPs) in a sonic bath were dispersed well in a solution of monomers. It is demonstrated that using ionic liquids (ILs) could help the NPs to disperse in polymer chains when they are forming by in-situ polymerization method. Good cooperation between organic and inorganic phases is one of the important roles of ILs in preparing of nanocomposites.

\section{XRD and SEM images}

According to the X-ray diffraction studies and SEM images, a good quality of

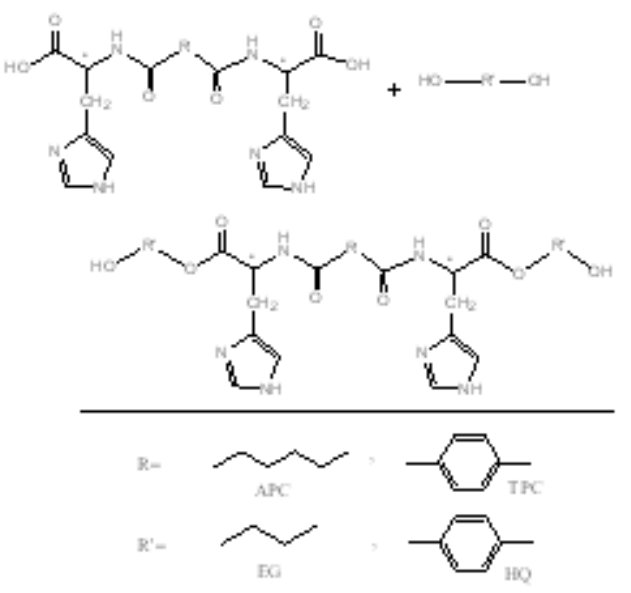

Fig. 3. Synthesis of polyester-polyols

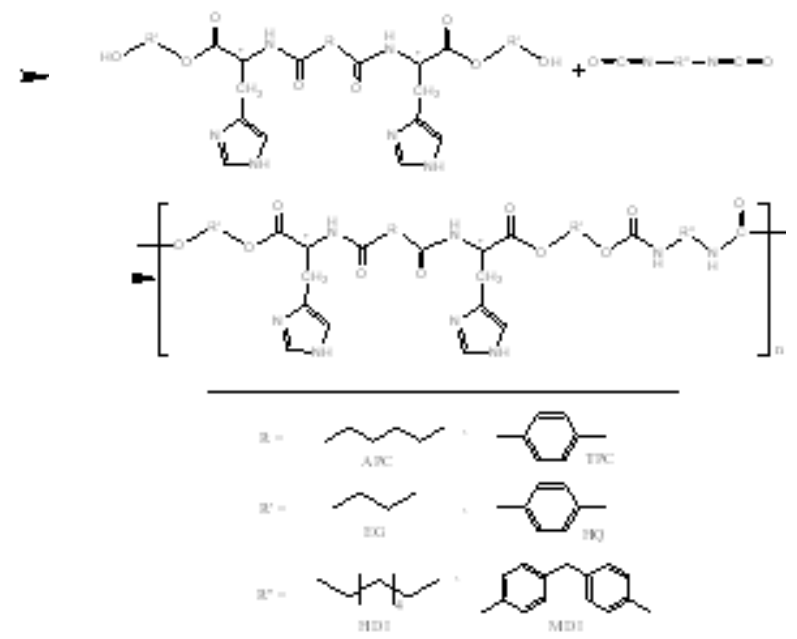

Fig. 4. Synthesis of poly(ester-amide-urethane)s

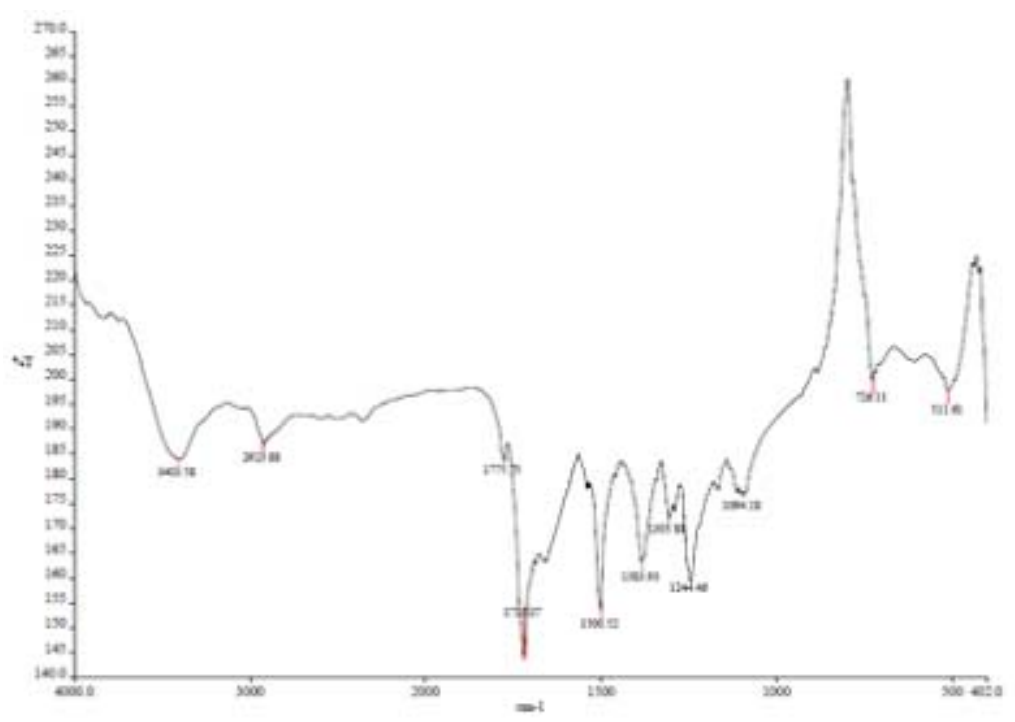

Fig. 5. FT-IR spectrum of optically active polyurethane (TPC-EG-HDI) 
magnetic NPs and their good distribution of them in nanocomposites achieved due to good properties. The SEM images are illustrated in figure (6) show synthesis of $\mathrm{Fe}_{3} \mathrm{O}_{4}$ in nano scale and good distribution on matrix.

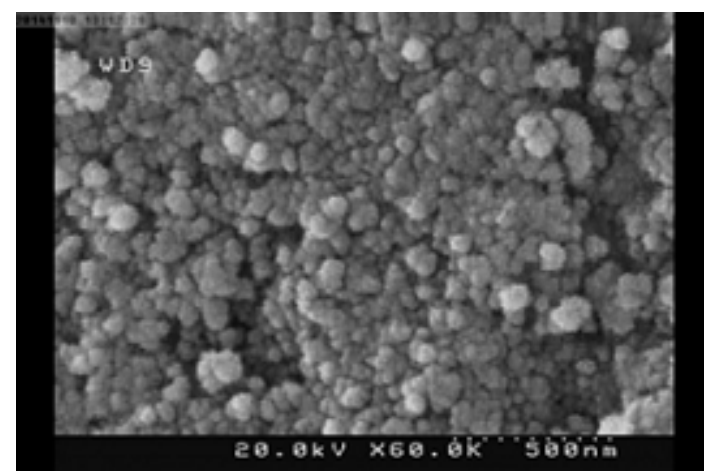

\section{Thermally properties of nanocomposites}

The results showed that thermal resistance of PUs was enhanced with adding more $\mathrm{Fe}_{3} \mathrm{O}_{4}$ NPs in composites. Preparation of a homogenuse composite $30 \%$ wt. $\mathrm{Fe}_{3} \mathrm{O}_{4}$ was possible

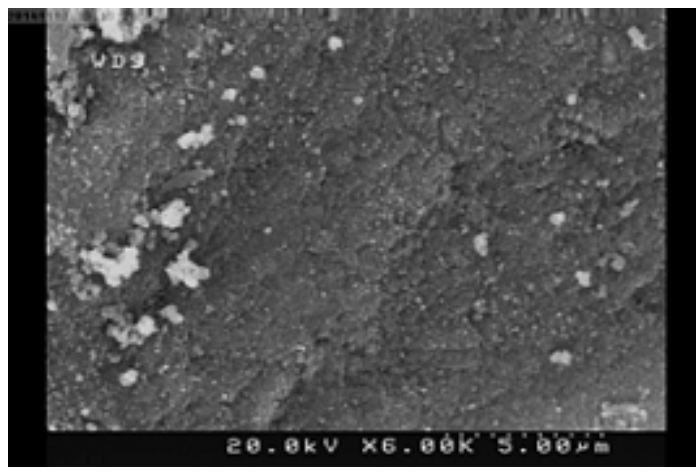

Fig. 6. SEM images of $\mathrm{Fe}_{3} \mathrm{O}_{4}$ NPs and composie
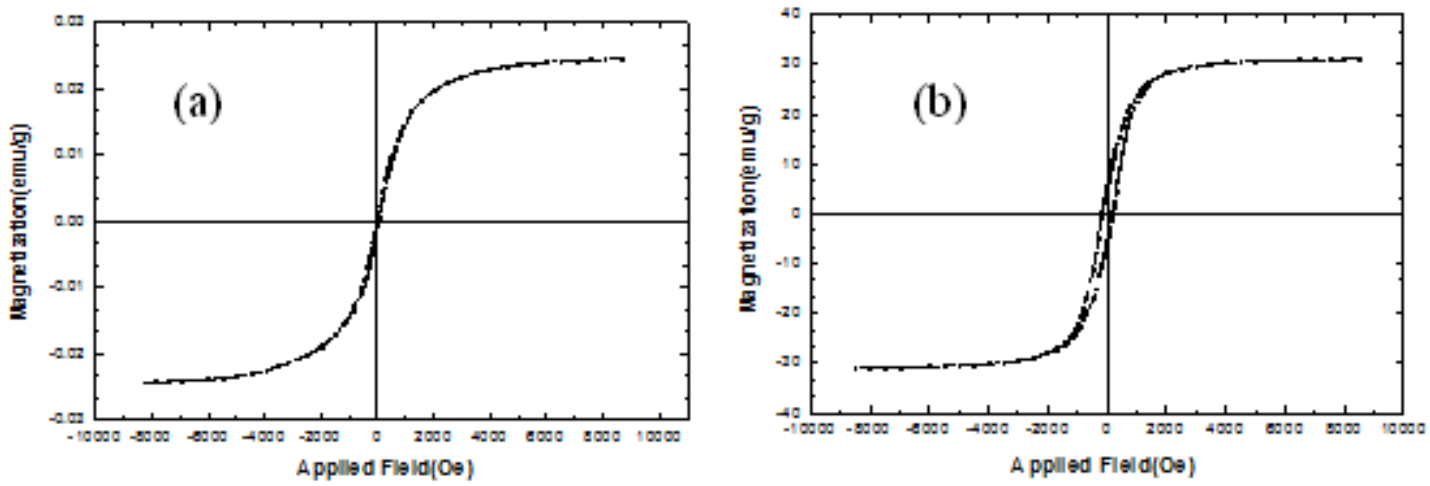

Fig. 7. Magnetic hysteresis loop of polymer (a) and $\mathrm{PU} / \mathrm{Fe}_{3} \mathrm{O}_{4} 30 \%$ NCs (b)

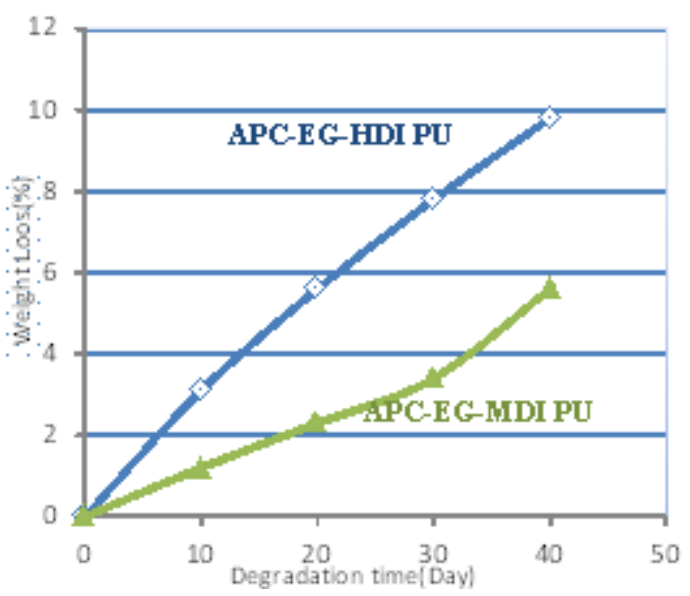

Fig. 8. Weight lose percentages of polyurethanes

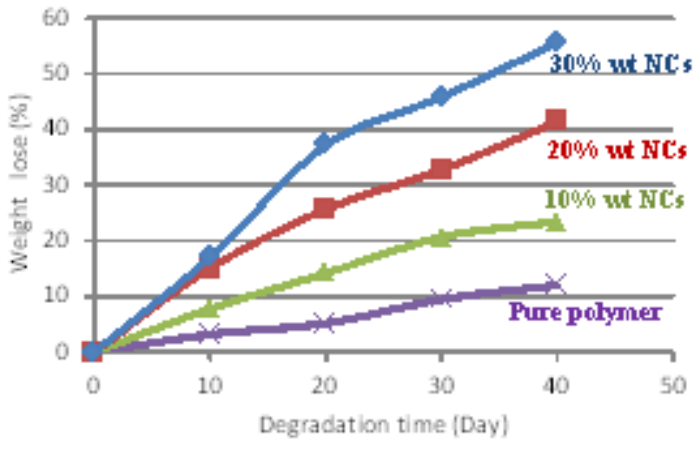

Fig. 9. Weight lose percentages of polyurethane $/ \mathrm{Fe}_{3} \mathrm{O}_{4}$ nanocomposites graphs 
via using ethyl methyl imidazolium bromide as IL and a disperss agent. Thease ionic molecules with hydrogen bondsand polar-polar intraction coverd the NPs to avoid agglomerization and make an uniform composite materials. Although increasing in size of NPs or agglomerization in nanocomposites, cause difficulties in thermal and mechanical properties. TGA curves for APC-EGHDI PU were showed improving in thermal properties, with increasing NPs weight percentages. Thermal behaviors of polymers were investigated using DSC technique. Polyurethane with $30 \%$ wt of $\mathrm{Fe}_{3} \mathrm{O}_{4}$, revealed highest and the pure PUs showed lowest glass transition temperature among the prepared polymer based nanocomposites. Also as it should be mention that, polymers obtained through IL method revealed higher thermal stability in comparison to the same nanocomposites obtained without any dispersing agent. It was attributed to the higher dipole-dipole interaction of polymer chains and backbones with NPs.

\section{Magnetic properties}

The magnetic $\mathrm{Fe}_{3} \mathrm{O}_{4}$ NPs are ferromagnetic. This substance in the absence of an external magnetic field has a spontaneous magnetization and unlike paramagnetism, their magnetic moments interact with themselves. It has magnetism and permanent magnet attract. The orientation of magnetization is in a direction completely.

Since the magnetic NPs spread in to the polymer, the magnetic properties of nanocomposites were enhanced. This property, compared with pure polymer through a conventional magnetic field by magnet. In this

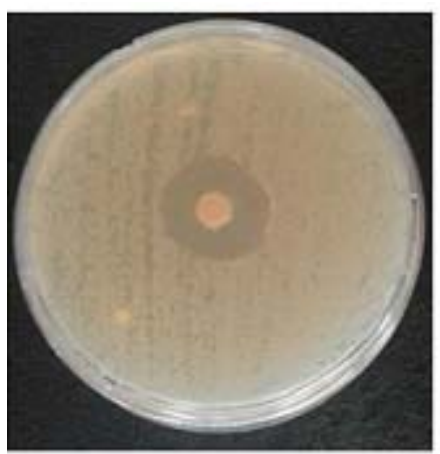

S.aur

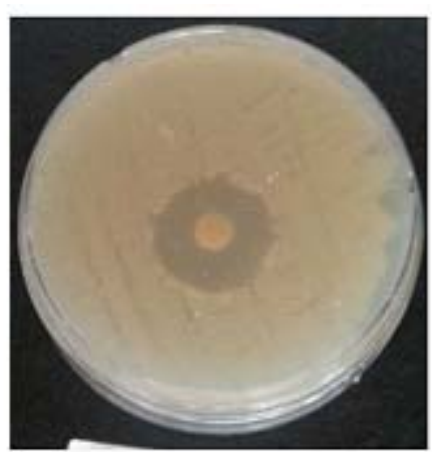

E coli experiment, the $\mathrm{PU} / \mathrm{Fe}_{3} \mathrm{O}_{4}$ nanocomposites drawn and attracted to the magnet more. It can be seen that with increasing magnetic NPs in the polyurethane matrix, composites tend to be more magnets. When the magnetic composite sample, is into magnetic field, magnetization increases fast. By increasing the applied magnetic field, magnetization increases acceleration decreases. This deceleration continues until its medium magnetization reach to Ms saturation. As magnetic hysteresis loop of pure $\mathrm{PU}$ (a) and $\mathrm{PU} / \mathrm{Fe}_{3} \mathrm{O}_{4} 30 \%$ wt. NCs (b) are illustrated in Figure (7), magnetism can be increased compared to pure polymer substrate.

\section{Biodegradation of polyurethane nanocomposites (PU-NCs)}

Hydrolytic degradation of samples that include weight loss percentage of samples in phosphate-buffered saline (PBS) with respect to time was evaluated as a measure of the rate of biodegradation. The percentage of weight loss relative to the initial weight of the samples was calculated by the following formula:

wight loss $(\%)=\frac{\text { The dry collected sample from the buffer solution }}{\text { The initial weight of the dry sample }}$

However, thermal stability and mechanical strength of polyurethanes synthesized from fully aromatic monomers were not compatible with other polymers, optically active linkages in polyurethane backbone effects on more biodegradability. Among the synthesized polymers, APC-EG-HDI PU with optically active property, showed a good degradation compare to the others as it illustrated in figure (8). Anyway, presence of the aliphatic bonds in polymer chains causes the biodegradability. In addition, using some weight

Fig. 10. Comparative antibacterial effect of optically active PU-Fe ${ }_{3} \mathrm{O}_{4} \% 10$ in presence of three pathogens; S. aur, E. coli, and Kleb 
percentage of $\mathrm{Fe}_{3} \mathrm{O}_{4}$ magnetic nano particles in polymer matrix defenately accelerates its rate. This property will be more and more with gradual increasing the greater the amount of $\mathrm{Fe}_{3} \mathrm{O}_{4}$ into composite. The $30 \%$ wt. $\mathrm{Fe}_{3} \mathrm{O}_{4}$ PU composite showed more degradation rate than $20 \%$ wt., $10 \%$ wt. and $5 \%$ wt. of magnetic $\mathrm{Fe}_{3} \mathrm{O}_{4}$ nanoparticles in polymer matrix with more lose weight in the same time, respectively as it shown in figure (9).

\section{Anti-bacterial properties}

Anti-bacterial property is one of the significant properties in medical, food and packaging industries. It is demonstrated that most NPs have this feature. Hence, presence of the magnetic $\mathrm{Fe}_{3} \mathrm{O}_{4}$ NPs showed it. Anti-bacterial investigation was done with 5 types of pathogens; listeria mono-cytogenes Escherichia coli, Bacillus subtilis, Staphylococcus aureus, and Shigella dysentery. About 1.0 grams of the composites were used in this experiment.

Halo forming around the discs showed a broadly anti-bacterial and anti-bacterial absence of aura indicates a lack of this combination. The halo was engendered around the most samples with pathogens which proved their anti-bacterial feature (figure 10).

\section{CONCLUSION}

Novel polyurethanes containing optically active monomers were prepared using pre-polymer method. Introducing hydrolysable ester, optically active carbon, thermally stable amide, and bulky pendant imidazole units into the polymer backbone disturbed inherent macromolecular degradedly, inter-chain hydrogen bonding, packing efficiency that caused superior properties. In this way, ZVI nano-particles that were synthesized by coprecipitation method were isolated in the polymeric matrix. Using ionic liquid in preparation of nanocomposites was so effect on homogeneous distribution of NPs in polyurethane matrix. Hence, to increase weight percentages of $\mathrm{Fe}_{3} \mathrm{O}_{4}$ some properties such as thermally resistance, magnetic, optically active, biocompatibility, and biodegradability were gradually developed. The obtained composites showed appropriate biodegradation that was attributed to the bio nature of amino acid moieties, hydrolysable ester and urethane bonds and biocompatible magnetic NPs simultaneously. Presence of $\mathrm{Fe}_{3} \mathrm{O}_{4}$ magnetic nanoparticles makes the anti-bacterial composites for using medical devices.

\section{ACKNOWLEDGMENTS}

This project, with support and funding from research section at the Islamic Azad University, Saveh branch was done.

\section{REFERENCES}

1. Krushna Chandra Pradhan and P. L. Nayak, Synthesis and Characterization of Polyurethane Nanocomposite from Castor Oil- Hexamethylene Diisocyanate (HMDI), Advances in Applied Science Research, 2012; 3(5): 3045-3052.

2. D.K. Chattopadhyay1, K.V.S.N. Raju, Structural engineering of polyurethane coatings for high performance applications, Prog. Polym. Sci., 2007; 32: 352-418.

3. Piotr Krol, Synthesis methods, chemical structures and phase structures of linear polyurethanes, Properties and applications of linear polyurethanes in polyurethane elastomers, copolymers and ionomers, Progress in Materials Science, 2007; 52: 915-1015.

4. Meng-Shung Yen, Ping-Yuan Tsai, Study on polyethylene glycol/polydimethylsiloxane mixing soft-segment waterborne polyurethane from different mixing processes, Journal of Applied Polymer Science, 2003; 90(1): 233-243.

5. J. Blackwell, M.R. Nagarajan, Conformational analysis of poly(MDI-butandiol) hard segment in polyurethane elastomers, Polymer, 1981; 22(2): 202-208.

6. Costas Methenitis, Georges Pneumatikakis, Marinos Pitsikalis, Joëlle Morcellet, Michel Morcellet, Polymers with amino acids in their side chain: Conformation of poly $(\mathrm{N}$ methacryloyl-L-methionine), Journal of Polymer Science Part A Polymer Chemistry, 1995; 33(13): 2233-2239,.

7. Tae Oan Ahn Seo, k Choi, Sang Won Lee, and Han Mo Jeong, Thermal and mechanical properties of poly(ether urethane) modified by copolyamide segments, Macromolecular Chemistry and Physics, 1994; 195(7): 25592567.

8. Chengde Liu, Zhongxing Zhang, Kerh Li Liu, Xiping $\mathrm{Ni}$ and Jun Li, Biodegradable thermogelling poly(ester urethane)s consisting of poly(1,4-butylene adipate), poly(ethylene glycol), and poly(propylene glycol), Soft 
Matter, 2013; 9: 787-794.

9. A. Nakkabi ; M. Sadiki ; M. Fahim; N. Ittobane; S. IbnsoudaKoraichi ; H. Barkai ; S. El abed, Biodegradation of Poly(ester urethane)s by Bacillus subtilis, Int. J. Environ. Res., 2015; 9(1): 157-162.

10. Tzong-Liu Wang and Fang-Jung Huang, Synthesis and properties of poly(amide-imideurethane) thermoplastic elastomers, Polymer International, 1998; 46(4): 280-284.

11. Iwona Zarzyka, The Modification of Polyurethane Foams Using New Boroorganic Polyols (II) Polyurethane Foams from BoronModified Hydroxypropyl Urea Derivatives, The Scientific World Journal, 2014, Article ID 363260, 9 pages.

12. Shahram Mehdipour-Ataei, Elaheh Gharehkhani, Preparation of novel pyridine-based poly(ether amide)s via three different routes and investigation of their properties, High Performance Polymers 2013; 25: 778-789.

13. Elaheh Gharekhani, Shahram Mehdipour-Ataei, and Masoud Taghi-Ganji, Soluble and Thermally Stable New Pyridine-based Poly(Ether Imide)s Synthesized Through Conventional and Ionic Liquid Methods, Iranian Polymer Journal, 2011; 20(6): 491-502.

14. P. Bruin, G. J. Veenstra, A. J. Nijenhuis andA. J. Pennings, Design and synthesis of biodegradable poly(ester-urethane) elastomer networks composed of non-toxic building blocks, Rapid Communications, 1988; 9(8): 589-594,.

15. Xiaoxia Lia, Hongguo Xiea, Junzhang Lina, Weiyang Xie, Xiaojun Ma, Characterization and biodegradation of chitosan-alginate polyelectrolyte complexes, Polymer Degradation and Stability, 2009; 94(1): 1-6.

16. Afsaneh Lavasanifara, John Samuela, Glen S Kwon, Poly(ethylene oxide)-block-poly(l-amino acid) micelles for drug delivery, Advanced Drug Delivery Reviews, 2002; 54(2): 169-190.

17. Hironobu Murata, Fumio Sanda , and Takeshi Endo, Syntheses and Radical Polymerization Behavior of Methacrylamides Having Peptide Moieties: Effect of the Methylene Chain Introduced between the Methacrylamide and Peptide Moieties on the Polymerizability and Polymer Structure, Macromolecules, 1997; 30(10): 2902-2906.

18. Shadpour Mallakpour, Fatemeh Rafiemanzelat, Synthesis and Characterization of Novel Optically Active Poly(ether-urethane)s Modified by Copoly(amide-imide) Segments based on Amino Acid through Diisocyanate Route: Influence of Reaction Parameters, Iranian Polymer, 2006; 15(1): 79-90.
19. Khalil Faghihi, Morteza Absalar, Mohsen Hajibeygi, New optically active and thermally stable poly(amide-imide)s containing N,N'(Bicyclo[2, 2, 2 ] oct - 7 - en e-2, 3, 5,6tetracarboxylic)-bis-L-alanine and aromatic diamines: synthesis and characterization, $J$. Braz. Chem. Soc. 2009; 20: 10.

20. Shadpour Mallakpour, Mohammad Hassan Shahmohammadi, Synthesis of New Optically Active Poly(amide-imide)s Derived from N,N'(pyromellitoyl)-bis-S-valine Diacid Chloride and Aromatic Diamines under Microwave Irradiation and Classical Heating, Iranian Polymer, 2005; 14(5): 473-483.

21. Shadpour Mallakpour, Fatemeh Rafiemanzelat, Synthesis and Properties of Novel Optically Active Poly(amide imide urethane) Thermoplastic Elastomers by the Reaction of a L-Leucine Based Diacid Chain Extender and PEG-terminated MDI, Iranian Polymer Journal, 2005; 14(2): 169-180.

22. Shadpour Mallakpour, Elaheh Kowsari, Synthesis and characterization of new optically active poly(amide-imide)s containing epiclon and L-methionine moieties in the main chain, Polymers for Advanced Technologies, 2005; 16(10): 732-737,.

23. Shadpour Mallakpour, Elaheh Kowsari, Soluble novel optically active poly(amide-imide)s derived from N,N2 -(4,42 -oxydiphthaloyl)-bisL-leucine diacid chloride and various aromatic diamines: Synthesis and characterization, Journal of Applied Polymer Science, 2005; 96(2): 435-442.

24. P. Bruin, G. J. Veenstra, A. J. Nijenhuis andA. J. Pennings, Design and synthesis of biodegradable poly(ester-urethane) elastomer networks composed of non-toxic building blocks, Rapid Communications, 1988; 9(8): 589-594.

25. Janne Kylmä and Jukka V. Seppälä, Synthesis and Characterization of a Biodegradable Thermoplastic Poly(ester"urethane) Elastomer, Macromolecules, 1997; 30(10): 2876-2882.

26. Jianjun Guan1, Michael S. Sacks2, Eric J. Beckman3 andWilliam R. Wagner, Synthesis, characterization, and cytocompatibility of elastomeric, biodegradable poly(esterurethane)ureas based on poly(caprolactone) and putrescine, Journal of Biomedical Materials Research, 2002; 61(3): 493-503.

27. Xian Jun Loha, b, Yun Xuan Tanb, Ziyun Lic, Lin Shin Teod, Suat Hong Gohd, Jun Li, Biodegradable thermogelling poly(ester urethane)s consisting of poly(lactic acid) Thermodynamics of micellization and hydrolytic degradation, Biomaterials, 2008; 29(14): 2164 
2172.

28. Suresh S. Umare, Ajay S. Chandure, Synthesis, characterization and biodegradation studies of poly(ester urethane)s, Chemical Engineering Journal, 2008; 142(1): 65-77.

29. Thorsten Pretsch, , Ines Jakob, Werner Müller, Hydrolytic degradation and functional stability of a segmented shape memory poly(ester urethane), Polymer Degradation and Stability, 2009; 94(1): 61-73.

30. M. Sabzi, S.M. Mirabedini, , J. Zohuriaan-Mehr, M. Atai, Surface modification of $\mathrm{TiO}_{2}$ nanoparticles with silane coupling agent and investigation of its effect on the properties of polyurethane composite coating, Progress in Organic Coatings, 2009; 65(2): 222-228.

31. T. O. Siyanbola, K. Sasidhar, B. V. S. K. Rao, Ramanuj Narayan, O. Olaofe, E. T. Akintayo, K. V. S. N. Raju, Development of Functional Polyurethane-ZnO Hybrid Nanocomposite Coatings from Thevetia peruviana Seed Oil, $J$ Am Oil Chem Soc, 2015; 92: 267-275.

32. Xiaoyan Gao, Yanchao Zhu, Xu Zhao, Zichen Wang, Dongmin An, Yuejia Ma, Shuang Guan, Yanyan Du, Bing Zhou, Synthesis and characterization of polyurethane/ $\mathrm{SiO}_{2}$ nanocomposites, Applied Surface Science, 2011; 257(10): 4719-4724

33. Beauty Das, Manabendra Mandal, Aadesh Upadhyay, Pronobesh Chattopadhyay and Niranjan Karak, Bio-based hyperbranched polyurethane $/ \mathrm{Fe}_{3} \mathrm{O}_{4}$ nanocomposites: smart antibacterial biomaterials for biomedical devices and implants, Biomedical Materials, 2013; 8: 3. http://dx.doi.org/10.1088/1748-6041/8/3/ 035003.

34. Abbas Mohammadi, Mehdi Barikani, Mohammad Barmar, Effect of polyol structure on the properties of the resultant magnetic polyurethane elastomer nanocomposites, Polymers for Advanced Technologies, 2013; 24(11): 978-985.
35. Abbas Mohammadi, Mehdi Barikani, Mohammad Barmar, Synthesis and investigation of thermal and mechanical properties of in situ prepared biocompatible $\mathrm{Fe}_{3} \mathrm{O}_{4} /$ polyurethane elastomer nanocomposites, Polymer Bulletin, 2015; 72(2): 219-234.

36. X. X. Xu, Y. F. Zheng, "Synthesis and Characterization of Magnetic Nanoparticles and Their Reinforcement in Polyurethane Film”, Key Engineering Materials, 2006; 324-325: 659-662.

37. Zhanhu Guo, Sung Park, H. Thomas Hahn, Suying Wei, Monica Moldovan, Amar B. Karki and David P. Young, Magnetic and electromagnetic evaluation of the magnetic nanoparticle filled polyurethane nanocomposites, J. Appl. Phys. 2007; 101: 09M511. http://dx.doi.org/10.1063/1.2711074.

38. Abbas Mohammadia, Mehdi Barikanib, Moslem Mansour Lakouraj, Biocompatible polyurethane/ thiacalix[4] arenes functionalized $\mathrm{Fe}_{3} \mathrm{O}_{4}$ magnetic nanocomposites: Synthesis and properties, Materials Science and Engineering: C, 2016; 66: 106-118.

39. Abbas Mohammadi, Mehdi Barikani, Mohammad Barmar, Effect of surface modification of $\mathrm{Fe}_{3} \mathrm{O}_{4}$ nanoparticles on thermal and mechanical properties of magnetic polyurethane elastomer nanocomposites, Journal of Materials Science, 2013; 48(21): 7493-7502.

40. Haifeng Zhuang, Hongjun Han, Peng Xu, Baolin Hou, Shengyong Jia, Dexin Wang, Kun Li, Biodegradation of quinoline by Streptomyces sp. N01 immobilized on bamboo carbon supported $\mathrm{Fe}_{3} \mathrm{O}_{4}$ nanoparticles, Biochemical Engineering Journal, 2015; 99: 44-47.

41. Lincheng Zhou, Guiying Li, Taicheng An, Yanfeng Li, Synthesis and characterization of novel magnetic $\mathrm{Fe}_{3} \mathrm{O}_{4}$ /polyurethane foam composite applied to the carrier of immobilized microorganisms for wastewater treatment, Research on Chemical Intermediates, 2010; 36(3): 277-288. 